\title{
Potential competing interest
}

\author{
Robert West ${ }^{1}$ \\ 1 University College London, University of London
}

\section{Definitions}

Competing interest

Defined by Robert West

Personal attribute

Defined by Robert West

A personal attribute that could be a competing interest.

Curator note: The definition was adapted from the PLOS definition. For source see Competing interest

Elaboration: Potentially competing interests should be fully disclosed by people in any research, clinical, professional or policy-making role to enable stakeholders to make an informed judgement about the potential for bias. They include: 1) financial potential competing interests, as well as 2) potentially being personally affected by, 3) having close friends, colleagues or relations who may be affected by, 4) having strong values relating to, 5) acting as an advisor to an organisation that may be affected by, and 6) being a member of a lobby group or pressure group relating to, the conduct of the professional role. 